\title{
Comparison of the Shear Bond Strength of Acid Etched and Er,Cr:YSGG Laser Irradiated IPS Empress II and Feldspathic Ceramic Surfaces to Metal Brackets: an in- Vitro Study
}

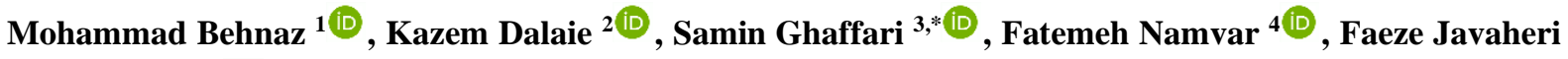 \\ Neyestanaki 4 ,*(D)
}

1 Associate Professor, Department of Orthodontics, School of Dentistry, Shahid Beheshti University of Medical Sciences, Tehran, Iran; behnaz1357@yahoo.com (M.B.);

2 Associate Professor, Department of Orthodontics, School of Dentistry, Shahid Beheshti University of Medical Sciences, Tehran, Iran; kazemdalaie@gmail.com (K.D.);

3 Postgraduate Student of Orthodontics, Dentofacial Deformities Research Center, Research Institute of Dental Sciences, Shahid Beheshti University of Medical Sciences, Tehran, Iran; saminghaffari@gmail.com (S.G.);

4 Dental Student, School of Dentistry, Shahid Beheshti University of Medical Sciences, Tehran, Iran; fatemehnamvar58@yahoo.com (F.N.); faezejavaheri2@gmail.com (F.J.N.);

* Correspondence: saminghaffari@gmail.com (S.G.); faezejavaheri2@gmail.com (F.J.N.);

Scopus Author ID: 57214751947

Received: 5.09.2021; Revised: 22.10.2021; Accepted: 25.10.2021; Published: 20.11.2021

\begin{abstract}
In this experimental study, the effects of Er,Cr:YSGG laser on the shear bond strength (SBS) of brackets bonded to two ceramic surfaces (Feldspathic and IPS Empress II) were compared to hydrofluoric (HF) acid etching. 60 ceramic discs were prepared, including two groups: Feldspathic and IPS Empress II surfaces. In each group, the following subgroups were prepared: $2 \mathrm{~W}$ Er,Cr:YSGG laser, 2.5W Er,Cr:YSGG laser, and HF acid-etching. Ceramic primer and adhesive resin composite were applied and then light-cured to bond the ceramic cylinders to brackets. The samples were stored in distilled water for $24 \mathrm{~h}$ and then, thermocycled. SBS testing was performed with a universal testing machine. Two-way ANOVA was used to compare SBS among subgroups $(\mathrm{P}<0.05)$. The highest SBS was seen in feldspathic surfaces with HF preparation $(14.61 \pm 3.11 \mathrm{MPa})$. There was a significant difference in SBS between different surface treatments except between the laser groups of IPS Empress II. Also, feldspathic surfaces had significantly higher SBS than IPS Empress II in all groups except HF. Conventional surface treatment provides much stronger adhesion than laser regardless of the ceramic type. Er,Cr:YSGG laser is effective on the SBS of the feldspathic ceramics, but not in IPS Empress II ceramics. So, laser treatment can be recommended as a favorable setting for treating feldspathic surfaces.
\end{abstract}

Keywords: acid etching; Er,Cr:YSGG laser; feldspathic ceramic; IPS empress II ceramic; shear bond strength; orthodontic brackets.

(C) 2021 by the authors. This article is an open-access article distributed under the terms and conditions of the Creative Commons Attribution (CC BY) license (https://creativecommons.org/licenses/by/4.0/).

\section{Introduction}

Today, the number of adults seeking orthodontic treatment is increasing [1,2]. Moreover, laminate and ceramic veneers are increasingly used to provide reassuring aesthetics and resemble natural teeth [3]. So, brackets are increasingly being bonded to the surface of the ceramics; however, it can be complicated to bond metal brackets to the surface of ceramics due 
to their characteristics. Less porosity in ceramic veneers compared to natural tooth structure is another challenge; such a way that the glazed ceramic prevents micro retention [4,5]. It has been shown that ceramic type, adhesion agent, and surface treatment methods considerably affect the bond strength between ceramic and bracket [6]. As it seems, it is necessary to examine the more practical and durable bonding protocols in this context. Some approaches have been suggested to increase the bond strength of brackets to the ceramics, and these can be used separately or in combination. Some of these methods are acid etching, sandblasting, silica coating, diamond bur, silane primer, and various laser treatments. These physical and chemical methods are meant to increase the bonding surface and improve the retention of the ceramic veneers [7-12].

Etching with hydrofluoric acid (HF) or ammonium biofluoride can cause a good roughness, so the glass matrix is selectively removed, and the crystal structure is exposed [13]. However, HF has some undesirable properties; it is a toxic and caustic substance for soft tissue, and it must be carefully isolated when used in contact with soft tissue. It may cause necrosis of the living tissue, as well as damage to the ceramic surfaces [14].

Sandblasting also has its disadvantages as it needs special equipment, it causes patient discomfort, and there is the possibility of eye damage and contamination of the dental equipment [15]. It can also cause micro-cracks on the surface, which ultimately affect the strength and durability of the final bonding [16]. However, it has shown good bond strength for some ceramic types [17].

On the other hand, lasers are free of contamination, and no chemicals are needed [18]. Moreover, they do not cause pain and unintentional movements and have attracted attention for a while because of their technical sensitivity and also because of less risk of poisoning than conventional methods such as hydrofluoric acid [19]. Previously it has been shown that laser treatment can be the most effective method to increase the bond strength between ceramic and composite resin cement [20]. Various lasers are used in dentistry for surface preparation and restoration. Nd:YAG, Er:YAG, and $\mathrm{CO}_{2}$ lasers have been suggested as alternatives to $\mathrm{HF}$ etching [21]. Furthermore, it has been claimed that the Er,Cr:YSGG laser is suitable for soft tissue surgery and cutting dentin, enamel, and alveolar bone [22]. Also, it has been shown that this laser type can provide suitable bond strength between ceramic and old composite surfaces [23]. However, to the best of our knowledge, only a few studies have been performed to evaluate its effects on bond strength between metal brackets and ceramics surfaces [24-27], and there is no consensus on its setting and its effects on shear bond strength.

Considering the limitations of the conventional method and the great demand for other alternatives, more studies should be conducted to establish a better surface treatment approach. Also, in spite of various studies evaluating different laser treatments, there is still no consensus upon the best approach to obtain the required shear bond strength for different ceramic surfaces. Conclusively, this experimental study aimed to investigate the effect of hydrofluoric acid and Er,Cr:YSGG laser on the shear bond strength of metal orthodontic brackets bonded to IPS Empress II and Feldspathic ceramic surfaces.

\section{Materials and Methods}

Samples consisted of 60 ceramic blocks, including 30 IPS Empress II ceramic blocks (Ivoclar, Schaon, Liechtenstein) and 30 feldspathic ceramic blocks (VITA VMK Master M3, VITA Zahnfabrik H. Rauter GmbH \& Co., Bad Säckingen, Germany) with a diameter of 10 $\mathrm{mm}$ and a thickness of $1 \mathrm{~mm}$, were prepared according to the factory recommendations. Then 
the bonding surface of each ceramic disc was polished using a silicon carbide sanding sheet (600 Grit) (Wuxi, Yinli, Jiangsu, China) on a rotating metallographic polisher machine with water cooling (Isomet1000; Buehler, Lake Bluff), at $250 \mathrm{rpm}$ to remove superficial roughness and obtain a smooth surface, and then the surface was glazed. Next, blocks were ultrasonically cleaned in distilled water for 180 seconds and then air-dried to remove contaminants before surface preparation. Finally, ceramic blocks were randomly divided into six groups for surface preparation as follows:

Group FH: (control group) containing 10 feldspathic ceramic blocks which were etched with $9.5 \%$ hydrofluoric acid (buffered porcelain etch; Ultradent, South Jordan, USA) for 60 seconds, and then they were washed thoroughly for 1 minute to remove residual acid, and finally, they were air-dried.

Group FE2: consisted of 10 feldspathic ceramic blocks which were prepared with Er, Cr:YSGG laser (Millennium; Biolase Technology Inc., San Clemente, CA, USA) with a wavelength of $2.78 \mu \mathrm{m}$, energy of $300 \mathrm{~mJ}$, frequency of $50 \mathrm{~Hz}$ and power of $2 \mathrm{~W}$ (steam and air pressures were adjusted up to 50\% of the laser unit), using an MZ10 fiber. The optical fiber of the laser was adjusted perpendicular to the samples at a distance of $1 \mathrm{~mm}$, and the desired surface was irradiated by manual back and forth movements for 60 seconds.

Group FE2.5: including 10 feldspathic ceramic blocks, which were prepared using Er,Cr:YSGG laser with the same energy parameters except with a power of $2.5 \mathrm{~W}$ and also with the same application.

Group IH: (control group) containing 10 IPS Empress II ceramic blocks which were etched with $9.5 \%$ hydrofluoric acid for 60 seconds and were washed for 1 minute and then dried.

Group IE2: consisted of 10 IPS Empress II ceramic blocks which were prepared using Er,Cr:YSGG laser with the same energy parameters and the same previous technique with a power of $2 \mathrm{~W}$, which was applied for one minute.

Group IE2.5: including 10 IPS Empress II ceramic blocks which were prepared using Er,Cr:YSGG laser with the same energy parameters and the same application as before, but with a power of $2.5 \mathrm{~W}$.

The samples prepared by laser application were then ultrasonically cleaned for 180 seconds and air-dried. In the next step, a bonding primer/sealer (Monobond-S, Ivoclar, Schaan, Liechtenstein) was applied to the prepared surfaces, and afterward, the surfaces were air-dried for 60 seconds. Bonding was performed by applying optical resin composite (American Orthodontics, Sheboygan, WI, USA) to maxillary incisor metal brackets, MBT slot 0.022" (Unitek Monrovia, Calif, USA), with dimensions of $2.90 \times 3.45 \mathrm{~mm}$ and inserting them on the center of the prepared surface of each sample with the same pressure calibrated by compression force gauge. The excess composite was removed from around the brackets with an explorer before curing. Polymerization was performed with a light cure device (XL3111, 3M ESPE, St Paul, MN, USA) with an intensity of $500 \mathrm{mw} / \mathrm{cm}^{2}$ from the occlusal and gingival edges of the brackets for 20 seconds. The samples were then stored in $37^{\circ} \mathrm{C}$ distilled water for 24 hours. All samples received 1000 thermal cycles at 5 and $55^{\circ} \mathrm{C}$, each cycle lasting 20 seconds (C1000 Touch, Thermal Cycler BIO-RAD, USA), to simulate the intraoral aging.

Rectangular cubic self-curing acrylic blocks were prepared to keep the bracket slots horizontal and in the same direction during the tests. Then the debonding force was measured using the Universal Testing Machine (AGS_X Autograph, Kyoto, Japan) with a blade speed of $1.5 \mathrm{~mm} / \mathrm{min}$ to debond the bracket from the ceramic. The bonded surface was perpendicular to 
the blade. The amount of shear bond strength (SBS) (MPa) was calculated by dividing the maximum separation force recorded at the moment of a debonding $(\mathrm{N})$ to the area of the bracket surface $(210 \mathrm{~mm} 2)$.

The resultant data were analyzed using SPSS software 26.0. Two-way ANOVA was utilized to determine the relationship between the mean of shear bond strength, ceramic type, and surface preparation. In the case of significant mutual effect between the ceramic type and the type of preparation, a comparison was made between the shear bond strength of different preparations in each type of ceramic and between two types of ceramics in each technique. To evaluate the presuppositions of the two-way ANOVA test, homogeneity of variances in groups was determined using Levene's test.

\section{Results}

Descriptive analysis of SBS of each group is mentioned in Table 1 and illustrated as a bar chart in Figure 1. As seen in Figure 1, the greatest mean of SBS was observed in FH group, followed by IH group, which both had the highest SBS in each ceramic group. Also, the lowest SBS has belonged to IE2.5 group, which had the lowest SBS in IPS Empress II ceramics. The lowest SBS in feldspathic ceramics was observed in FE2 group.

Table 1. Descriptive analysis of SBS of each group.

\begin{tabular}{|c|c|c|c|c|c|c|}
\hline Groups & Number & Mean & SD & $\begin{array}{c}\text { Standard } \\
\text { error }\end{array}$ & $\min$ & $\max$ \\
\hline $\mathrm{FH}$ & 10 & 14.61 & 3.11 & 0.98 & 9.15 & 18.59 \\
\hline FE2 & 10 & 9.15 & 2.50 & 0.48 & 5.30 & 13.59 \\
\hline FE2.5 & 10 & 11.89 & 2.29 & 0.72 & 8.43 & 15.21 \\
\hline $\mathrm{IH}$ & 10 & 13.64 & 2.09 & 0.52 & 10.44 & 16.57 \\
\hline IE2 & 10 & 2.39 & 1.39 & 0.43 & 1.02 & 5.00 \\
\hline IE2.5 & 10 & 2.71 & 1.51 & 0.44 & 1.89 & 5.77 \\
\hline
\end{tabular}

\section{Shear Bond Strength}

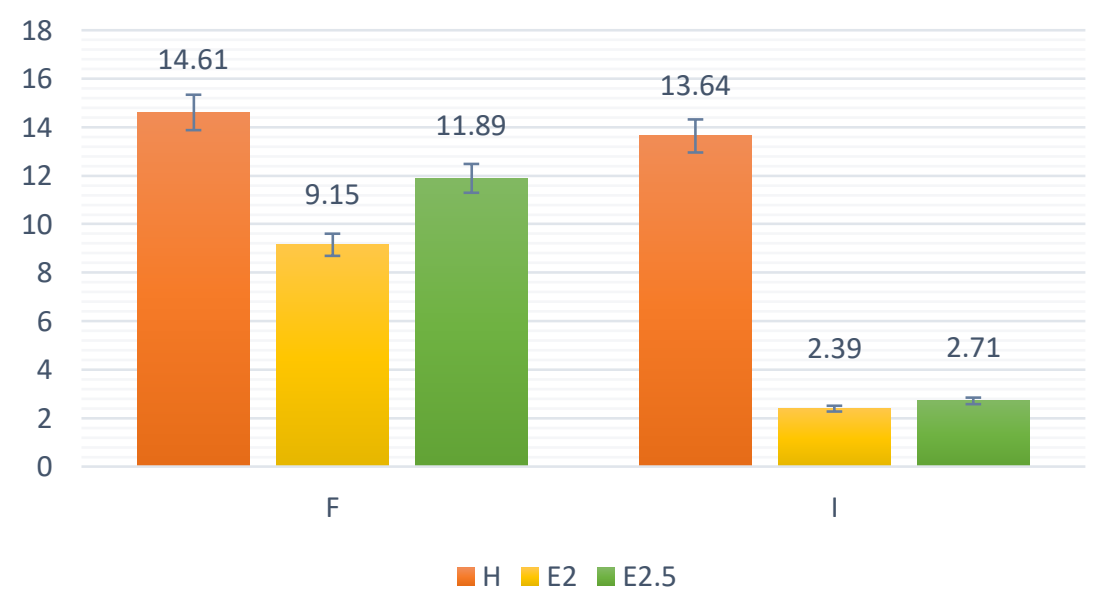

Figure 1. Diagram of SBS of orthodontic brackets to ceramic discs. The chart represents the mean of SBS in each group with percentage error bars (5\%).

According to the results of two-way ANOVA, laid out in Table 2, in the feldspathic ceramic group, the difference between all subgroups was significant $(\mathrm{P}$ value $<0.02)$. In IPS Empress II ceramic group, the difference between IE2 and IE2.5 was insignificant (P value $=1.000)$, but the difference between others was significant $(\mathrm{P}$ value $<0.001)$. 
Table 2. Comparison of SBS of different surface preparations in each type of ceramic.

\begin{tabular}{|c|c|c|c|c|}
\hline Ceramic type & \multicolumn{2}{|c|}{ Preparation type } & Mean difference & $P$ value \\
\hline \multirow{3}{*}{ Feldspathic } & \multirow{2}{*}{ FH } & FE2 & 6.262 & $0.000^{*}$ \\
\hline & & FE2.5 & 2.726 & $0.014^{*}$ \\
\hline & FE2 & FE2.5 & 3.536 & $0.001^{*}$ \\
\hline \multirow{3}{*}{ IPS Empress II } & \multirow{2}{*}{$\mathrm{IH}$} & IE2 & 11.058 & $0.000^{*}$ \\
\hline & & IE2.5 & 10.649 & $0.000^{*}$ \\
\hline & IE2 & IE2.5 & 0.409 & 1.000 \\
\hline
\end{tabular}

Also, as seen in Table 3, in surface preparation with HF, there is no significant difference between feldspathic and IPS Empress II ceramics ( $P$ value=0.216). However, in surface preparation with Er,Cr:YSGG at 2 and $2.5 \mathrm{~W}$, feldspathic ceramics had significantly higher SBS than IPS Empress II ceramics (P value $<0.001$ in both).

Table 3. Comparison of SBS between two types of ceramic in each preparation technique.

\begin{tabular}{c|c|c|c|c} 
Preparation type & \multicolumn{2}{|c|}{ Ceramic type } & Mean difference & P value \\
\hline H & F & I & 1.159 & 0.216 \\
\hline E2 & F & I & 5.955 & $0.000^{*}$ \\
\hline E2.5 & F & I & 9.082 & $0.000^{*}$ \\
F: feldspathic, I: IPS Empress II, H: HF, E2: 2 watts Er,Cr:YSGG, E2.5: 2.5 watts Er,Cr:YSGG \\
* Statistically significant
\end{tabular}

\section{Discussion}

The present study is based on the hypothesis that the effect of Er,Cr;YSGG laser on bond strength of feldspathic and IPS Empress II ceramic surfaces is comparable or better than the effect of hydrofluoric acid on them. This hypothesis was rejected in both ceramics and surface treatment with the conventional technique, HF etching, which led to significantly greater bond strength. Er,Cr:YSGG laser irradiation provided the minimum acceptable bond strength for orthodontic brackets, which is 5.9 up to $7.8 \mathrm{MPa}$ according to Reynolds [28], only in feldspathic ceramics, and it was greater at $2.5 \mathrm{~W}$ in comparison to $2 \mathrm{~W}$. Whereas, in IPS Empress II ceramics only surface treatment through HF etching exhibited an acceptable bond strength to metal brackets and laser application, regardless of its power, was inefficient.

Micromechanical retention of the ceramic surfaces is of great importance for bonding with adhesive agents, and several techniques have been reported to improve the ceramic surfaces, including sandblasting with aluminum oxide particles [29], acid etching [30], and also a combination of these methods. These techniques are especially difficult and ineffective for high-alumina or zirconia-reinforced ceramics because they lack the crystalline phase of silica. Therefore, other techniques such as silica coating were introduced [31]. However, the ceramics used in our study (IPS Empress II and feldspathic ceramics) contain the crystalline phase of silica within their structure, and successful results with hydrofluoric acid treatment can be achieved.

Although surface treatment with hydrofluoric acid has been used extensively in the past, it can cause drastic side effects in clinics. HF etching used in dentistry, mostly with a concentration of 5-15\%, requires great isolation with a rubber dam or dental dam in order to prevent soft tissue damage while contacting adjacent soft tissues [32]. Also, acute symptoms such as skin burns, respiratory complications, and eye injuries may occur at higher concentrations [33]. So, alternative and less invasive techniques for the preparation of ceramic surfaces should be researched and used clinically. 
One of the less invasive techniques in this context is preparing ceramic surfaces with laser irradiation. Different laser treatments have been introduced and evaluated previously, but there is still no consensus upon the best surface treatment technique to obtain greater bond strength. There is disagreement on laser type, but different laser powers can cause various results [34].

Najafi et al. [35] claimed that although surface treatment with super pulse $\mathrm{CO}_{2}$ did not lead to bond strength as great as HF etching, it is still acceptable to eliminate the etching process. On the other hand, Ahrari et al. [36] obtained higher bond strength through 10 and 15 W fractional $\mathrm{CO}_{2}$ laser in comparison to $\mathrm{HF}$ etching. Also, another study [37] confirmed that both $\mathrm{CO}_{2}$ and $\mathrm{Nd}$ :YAG lasers provide adequate bond strength for glass-ceramics. A study by Yassaei et al. [38] showed successful bond strength via the surface treatment of feldspathic porcelains with $1.8 \mathrm{~W}$ Er:YAG laser in comparison to conventional HF etching. Also, another study by Hosseini et al. [39] observed comparable bond strength between HF etching and 1.5 and $2 \mathrm{~W} \mathrm{Nd:YAG} \mathrm{laser} \mathrm{treatment} \mathrm{in} \mathrm{feldspathic} \mathrm{porcelains} \mathrm{and} \mathrm{suggested} \mathrm{this} \mathrm{method} \mathrm{for}$ porcelain etching before bracket bonding. Whereas, another study by Cevik et al. [40], compared the effect of different surface treatments on bond strength of feldspathic and lithium disilicate ceramics to metal brackets. They observed that in both types of ceramics, sandblasting results in the highest SBS and HF etching causes better bond strength than laser treatment with Nd:YAG. Although this study utilized different types of laser irradiation and ceramic, but its results are in line with the results of the present study. Also, another in-vitro study by Erdur et al. [41] compared the effects of different surface treatments including Ti:sapphire laser, Nd:YAG laser, Er:YAG laser, sandblasting, and HF etching on bond strength between metal brackets and ceramic surfaces (feldspathic and IPS Empress e-Max). The highest bond strength was observed after Ti:sapphire laser treatment, followed by sandblasting and HF etching; but Nd:YAG and Er:YAG lasers lead to the lowest SBS. So, as it is obvious, there is no specific protocol for surface treatment of ceramics before bracket bonding.

Another laser that is less used for surface treatment of porcelains is Er,Cr:YSGG. Alshahrani et al. [27] utilized this laser type for surface treatment of lithium disilicate ceramics before bonding them to metal brackets and compared it with $\mathrm{CO}_{2}$ laser, HF etching, and sandblasting. The highest SBS was observed in HF etching group, followed by Er,Cr:YSGG laser group. So, they suggested $\mathrm{Er}, \mathrm{Cr}$ :YSGG, and $\mathrm{CO}_{2}$ lasers as alternatives to $\mathrm{HF}$ etching for this ceramic type; a similar result to the study of Alqerban [42], who observed comparable bond strengths between this laser type and HF etching in lithium disilicate ceramics and recommended it as an alternative to conventional methods. In the present study as well, both ceramics with HF etching had the highest bond strength, but laser irradiation through Er,Cr:YSGG provided acceptable bond strength only in feldspathic ones. The results of the present study also confirm the findings by Mohammed et al. [43].

Another experimental study by Mirhashemi et al. [24] has evaluated surface treatment methods of feldspathic porcelains, including HF etching, $3 \mathrm{~W} \mathrm{Er,Cr:YSGG} \mathrm{irradiation} \mathrm{alone,}$ and after HF etching, and $3 \mathrm{~W}$ Er:YAG irradiation alone and after HF etching. Similar to the present study, conventional HF etching leads to the highest SBS to metal brackets. Also, HF etching before laser irradiation resulted in better bond strength compared to laser irradiation alone. Although both laser types had the lowest SBS, despite Er:YAG, Er,Cr:YSGG provided the minimum SBS required for orthodontic bonding. These results confirm the findings of the present study. Similar results were shown by Kursoglu et al. [25], who compared the effect of HF etching and Er,Cr:YSGG laser irradiation on bond strength between resin cement and 
disilicate lithium ceramic. They observed that HF etching provides better SBS than Er,Cr:YSGG laser, but if surface treatment through this laser type is desired, it will be more effective at 1.5 and $2.5 \mathrm{~W}$ rather than $6 \mathrm{~W}$. Zanjani et al. [26] also observed greater SBS between resin cement and zirconia ceramics through Er,Cr:YSGG laser irradiation at $3 \mathrm{~W}$ rather than $2 \mathrm{~W}$. Furthermore in the present study Er,Cr:YSGG laser irradiation at $2.5 \mathrm{~W}$ provided greater SBS in comparison to $2 \mathrm{~W}$, especially in feldspathic ceramics. Consequently, it seems that there is a threshold of laser power to accomplish greater bond strength through Er,Cr:YSGG laser application, which should be evaluated more extensively in future studies.

Another consideration in surface treatment application through Er,Cr:YSGG laser or other laser types is their permanent effect on ceramic structure and surface, which should be evaluated more accurately in different applications and different ceramic types. A study by Tarek et al. [44] claimed that Er,Cr:YSGG laser produces similar surface roughness in comparison to HF etching in lithium disilicate ceramics, but it causes negative changes on the surface topography of these ceramics. More studies should be done to clarify the effect of laser on the structure of the ceramics, such as Fourier-transform infrared spectroscopy (FTIR) before and after the laser exposer [45-47].

One of the great limitations of this study was the in-vitro evaluation of shear bond strength, considering that the pattern of debonding forces can be distinct between oral and laboratory qualifications. Also, in the present study, aging was conducted through only thermocycling, which does not resemble the influence of other factors in the oral environment such as saliva and mechanical aging by recurring occlusal contacts and forces over long periods of time. Furthermore, a more accurate evaluation of surface changes such as changes in surface roughness through scanning electron microscope would provide a better understanding of the influence of each method on micromechanical retention of ceramics, which should be assessed in future studies. Finally, considering the ineffectiveness of 2 and $2.5 \mathrm{~W} \mathrm{Er,Cr}$ :YSGG laser on SBS of IPS Empress II ceramic surfaces, wider ranges of power of this laser should be evaluated in further studies.

\section{Conclusions}

Although shear bond strength was greater when the conventional method of etching with hydrofluoric acid was used in both types of ceramics compared to Er,Cr:YSGG laser, but laser treatment provides an adequate bond strength between orthodontic brackets and feldspathic ceramic surfaces, especially when the laser power is proper; therefore, this method can be used as a beneficial method in clinical conditions as though it failed to develop the minimum of shear bond strength required for bonding the brackets to IPS Empress II ceramic surfaces in both values of power. So, more studies should be performed to develop an alternative method, which provides proper bond strength to this type of ceramic.

\section{Funding}

This research received no external funding.

\section{Acknowledgments}

There is no acknowledgment. 


\section{Conflicts of Interest}

The authors declare no conflict of interest.

\section{References}

1. Guazzato, M.; Albakry, M.; Ringer, S.P.; Swain, M.V. Strength, fracture toughness and microstructure of a selection of all-ceramic materials. Part II. Zirconia-based dental ceramics. Dental materials 2004, 20, 449456, https://doi.org/10.1016/j.dental.2003.05.002.

2. Meyer-Marcotty, P.; Klenke, D.; Knocks, L.; Santander, P.; Hrasky, V.; Quast, A. The adult orthodontic patient over 40 years of age: association between periodontal bone loss, incisor irregularity, and increased orthodontic treatment need. Clinical Oral Investigations 2021, 1-8, https://doi.org/10.1007/s00784-02103936-2.

3. Yilmaz, H.; Aydin, C.; Gul, B.E. Flexural strength and fracture toughness of dental core ceramics. The Journal of prosthetic dentistry 2007, 98, 120-128, https://doi.org/10.1016/S0022-3913(07)60045-6.

4. Piconi, C.; Maccauro, G. Zirconia as a ceramic biomaterial. Biomaterials 1999, 20, 1-25, https://doi.org/10.1016/S0142-9612(98)00010-6.

5. Labunet, A.; Kui, A.; Voina-Tonea, A.; Vigu, A.; Sava, S. Orthodontic Attachment Adhesion to Ceramic Surfaces. Clinical, Cosmetic and Investigational Dentistry 2021, 13, 83, https://dx.doi.org/10.2147\%2FCCIDE.S302770.

6. Juntavee, P.; Kumchai, H.; Juntavee, N.; Nathanson, D. Effect of Ceramic Surface Treatment and Adhesive Systems on Bond Strength of Metallic Brackets. International Journal of Dentistry 2020, 2020 https://doi.org/10.1155/2020/7286528.

7. Tinschert, J.; Zwez, D.; Marx, R.; Anusavice, K. Structural reliability of alumina-, feldspar-, leucite-, micaand zirconia-based ceramics. Journal of dentistry 2000, 28, 529-535, https://doi.org/10.1016/S03005712(00)00030-0.

8. Von Steyern, P.V.; Carlson, P.; Nilner, K. All-ceramic fixed partial dentures designed according to the DCZirkon ${ }^{\circledR}$ technique. A 2-year clinical study. Journal of Oral Rehabilitation 2005, 32, 180-187, https://doi.org/10.1111/j.1365-2842.2004.01437.x.

9. Alzainal, A.H.; Majud, A.S.; Al-Ani, A.M.; Mageet, A.O. Orthodontic Bonding: Review of the Literature. International Journal of Dentistry 2020, 2020, https://doi.org/10.1155/2020/8874909.

10. Abuelenain, D.A.; Linjawi, A.I.; Alghamdi, A.S.; Alsadi, F.M. The effect of various mechanical and chemical surface conditioning on the bonding of orthodontic brackets to all ceramic materials. Journal of Dental Sciences 2021, 16, 370-374, https://doi.org/10.1016/j.jds.2020.02.003.

11. Recen, D.; Yildirim, B.; Othman, E.; Comlekoglu, E.; Isil, A. Bond strength of metal brackets to feldspathic ceramic treated with different surface conditioning methods: an in vitro study. European Oral Research 2021, 55, 1-7, https://doi.org/10.26650/eor.20210004.

12. Mirhashmi, S.A.H.; Akhundi, M.S.A.; Ganji, S.M.P.; Allahdadi, M.; Norouzian, M.; Chiniforush, N. Optimized Er: YAG Laser Irradiation Distance to Achieve the Strongest Bond Strength Between Orthodontic Brackets and Zirconia-Ceramics. Journal of lasers in medical sciences 2020, 11, 287, https://dx.doi.org/10.34172\%2Fjlms.2020.48.

13. Giordano 2nd, R.A. CAD/CAM: overview of machines and materials. Journal of the Massachusetts Dental Society 2002, 51, 12-15, https://pubmed.ncbi.nlm.nih.gov/11949572/.

14. Sailer, I.; Feher, A.; Filser, F.; Lüthy, H.; Gauckler, L.J.; Schärer, P.; Hämmerle, C.H.F. Prospective clinical study of zirconia posterior fixed partial dentures: 3-year follow-up. Quintessence International 2006, 37, http://www.quintpub.com/userhome/qi/qi_37_9_Sailer_3.pdf.

15. Hämmerle, C.H. Success and failure of fixed bridgework. Periodontology 2000 1994, 4, 41-51, https://doi.org/10.1111/j.1600-0757.1994.tb00004.x.

16. Calamia, J. Etched porcelain veneers: the current state of the art. Quintessence International 1985, 16, 5-12, https://pubmed.ncbi.nlm.nih.gov/3883393.

17. Kabiri, S.; Neshati, A.; Rohani, B. Effect of Different Surface Treatments and Pressure Conditions on Shear Bond Strength of Zirconia Ceramic to Composite Resin. Frontiers in Dentistry 2021, 18, https://doi.org/10.18502/fid.v18i26.6936.

18. Stangel, I.; Nathanson, D.; Hsu, C. Shear strength of the composite bond to etched porcelain. Journal of dental research 1987, 66, 1460-1465, https://doi.org/10.1177/00220345870660091001. 
19. Güler, A.U.; Yilmaz, F.; Yenisey, M.; Güler, E.; Ural, Ç. Effect of acid etching time and a self-etching adhesive on the shear bond strength of composite resin to porcelain. Journal of Adhesive Dentistry 2006, 8 , https://www.researchgate.net/publication/7242909_Effect_of_acid_etching_time_and_a_selfetching_adhesive_on_the_shear_bond_strength_of_composite_resin_to_porcelain.

20. Da Silveira, B.L.; Paglia, A.; Burnett Jr, L.H.; Arai Shinkai, R.S.; Eduardo, C.D.P.; Spohr, A.M. Microtensile bond strength between a resin cement and an aluminous ceramic treated with Nd: YAG laser, Rocatec System, or aluminum oxide sandblasting. Photomedicine and laser surgery 2005, 23, 543-548, https://doi.org/10.1089/pho.2005.23.543.

21. Addison, O.; Marquis, P.M.; Fleming, G.J. The impact of hydrofluoric acid surface treatments on the performance of a porcelain laminate restorative material. Dental Materials 2007, 23, 461-468, https://doi.org/10.1016/j.dental.2006.03.002.

22. Aida, M.; Hayakawa, T.; Mizukawa, K. Adhesion of composite to porcelain with various surface conditions. The Journal of prosthetic dentistry 1995, 73, 464-470, https://doi.org/10.1016/S0022-3913(05)80076-9.

23. Farhadifard, H.; Rezaei-Soufi, L.; Farhadian, M.; Shokouhi, P. Effect of different surface treatments on shear bond strength of ceramic brackets to old composite. Biomaterials Research 2020, 24, 1-7, https://doi.org/10.1186/s40824-020-00199-y.

24. Mirhashemi, A.; Chiniforush, N.; Jadidi, H.; Sharifi, N. Comparative study of the effect of Er:YAG and Er:Cr;YSGG lasers on porcelain: etching for the bonding of orthodontic brackets. Lasers in Medical Science 2018, 33, 1997-2005, https://doi.org/10.1007/s10103-018-2573-y.

25. Kursoglu, P.; Motro, P.F.K.; Yurdaguven, H. Shear bond strength of resin cement to an acid etched and a laser irradiated ceramic surface. jap 2013, 5, 98-103, https://doi.org/10.4047/jap.2013.5.2.98.

26. Akhavan Zanjani, V.; Ahmadi, H.; Nateghifard, A.; Ghasemi, A.; Torabzadeh, H.; Abdoh Tabrizi, M.; Alikhani, F.; Razi, R.; Nateghifard, A. Effect of different laser surface treatment on microshear bond strength between zirconia ceramic and resin cement. Journal of investigative and clinical dentistry 2015, 6, 294-300, https://doi.org/10.1111/jicd.12105.

27. AlShahrani, I.; Kamran, M.A.; Almoammar, S.; Alhaizaey, A. Photosensitization of lithium di-silicate ceramic by Er, Cr: YSGG and fractional carbon dioxide laser bonded to orthodontic bracket. Photodiagnosis and Photodynamic Therapy 2019, 28, 273-276, https://doi.org/10.1016/j.pdpdt.2019.08.017.

28. Reynolds, I. A review of direct orthodontic bonding. British journal of orthodontics 1975, 2, 171-178, https://doi.org/10.1080/0301228X.1975.11743666.

29. Akay, C.; Okşayan, R.; Özdemir, H. Influence of various types of surface modifications on the shear bond strength of orthodontic brackets on Y-TZP zirconia ceramics. Journal of the Australian Ceramic Society 2020, 56, 1435-1439, https://doi.org/10.1007/s41779-020-00479-9.

30. Mokhtarpur, H.; Nafisifard, M.; Dadgar, S.; Etemadi, A.; Chiniforush, N.; Sobouti, F. Shear Bond Strength of the Metal Bracket to Zirconium Ceramic Restoration Treated by the Nd: YAG Laser and Other Methods: An In vitro Microscopic Study. Journal of lasers in medical sciences 2020, 11, 411-416, https://dx.doi.org/10.34172\%2Fjlms.2020.65.

31. Ban, S.; Anusavice, K. Influence of test method on failure stress of brittle dental materials. Journal of Dental Research 1990, 69, 1791-1799, https://doi.org/10.1177\%2F00220345900690120201.

32. Özcan, M.; Allahbeickaraghi, A.; Dündar, M. Possible hazardous effects of hydrofluoric acid and recommendations for treatment approach: a review. Clinical oral investigations 2012, 16, 15-23, https://doi.org/10.1007/s00784-011-0636-6.

33. Bajraktarova-Valjakova, E.; Korunoska-Stevkovska, V.; Georgieva, S.; Ivanovski, K.; BajraktarovaMisevska, C.; Mijoska, A.; Grozdanov, A. Hydrofluoric acid: burns and systemic toxicity, protective measures, immediate and hospital medical treatment. Open access Macedonian journal of medical sciences 2018, 6, 2257, https://dx.doi.org/10.3889\%2Foamjms.2018.429.

34. Labunet, A.; Kui, A.; Sava, S. Laser Use in Creating Orthodontic Adhesion to Ceramic Surfaces. Applied Sciences 2021, 11, 2512, https://doi.org/10.3390/app11062512.

35. Zarif Najafi, H.; Oshagh, M.; Torkan, S.; Yousefipour, B.; Salehi, R. Evaluation of the effect of four surface conditioning methods on the shear bond strength of metal bracket to porcelain surface. Photomedicine and laser surgery 2014, 32, 694-699, https://doi.org/10.1089/pho.2014.3782.

36. Ahrari, F.; Heravi, F.; Hosseini, M. CO2 laser conditioning of porcelain surfaces for bonding metal orthodontic brackets. Lasers in medical science 2013, 28, 1091-1097, https://doi.org/10.1007/s10103-0121152-x. 
37. Alavi, S.; Samie, S.; Raji, S.A.H. Comparison of lithium disilicate-reinforced glass ceramic surface treatment with hydrofluoric acid, Nd: YAG, and CO2 lasers on shear bond strength of metal brackets. Clinical Oral Investigations 2021, 25, 2659-2666, https://doi.org/10.1007/s00784-020-03576-y.

38. Yassaei, S.; Moradi, F.; Aghili, H.; Kamran, M. Shear bond strength of orthodontic brackets bonded to porcelain following etching with Er: YAG laser versus hydrofluoric acid. Orthodontics (Chic.) 2013, 14, e8287, https://doi.org/10.11607/ortho.856.

39. Hosseini, M.H.; Sobouti, F.; Etemadi, A.; Chiniforush, N. Shear bond strength of metal brackets to feldspathic porcelain treated by Nd: YAG laser and hydrofluoric acid. Lasers in medical science 2015, 30, 837-841, https://doi.org/10.1007/s10103-013-1458-3.

40. Cevik, P.; Karacam, N.; Eraslan, O.; Sari, Z. Effects of different surface treatments on shear bond strength between ceramic systems and metal brackets. Journal of Adhesion Science and Technology 2017, 31, 11051115, https://doi.org/10.1080/01694243.2016.1245074.

41. Erdur, E.A.; Basciftci, F.A. Effect of Ti: sapphire laser on shear bond strength of orthodontic brackets to ceramic surfaces. Lasers in surgery and medicine 2015, 47, 512-519, https://doi.org/10.1002/1sm.22371.

42. Alqerban, A. Lithium di silicate ceramic surface treated with Er,Cr:YSGG and other conditioning regimes bonded to orthodontic bracket. The Saudi Dental Journal 2021, 33, 188-193, https://doi.org/10.1016/j.sdentj.2019.11.012.

43. Mohammed, H.A.; Ali, O.S. Three-Dimensional Surface Evaluation and Shear Bond Strength of Three Pretreatment E-max Surfaces for Metal and Ceramic Orthodontic Brackets: In vitro Study. Polytechnic Journal 2020, 10, 113-118, https://doi.org/10.25156/ptj.v10n2y2020.pp113-118.

44. Tarek, M. Effect of Er, Cr: YSGG Laser Versus Acid Etching Surface Treatment on the Surface Roughness and Topography of Two Pressable Lithium Disilicate Ceramics.“In-Vitro Study”. Egyptian Dental Journal 2021, 67, 1571-1581, https://dx.doi.org/10.21608/edj.2021.63693.1507.

45. Atta, D.; Fakhry, A.; Ibrahim, M. Chitosan membrane as an oil carrier: Spectroscopic and modeling analyses. $\begin{array}{lllll}\text { Der Pharma } & \text { Chemica } & \text { 2015, } & \text { 357-361, }\end{array}$ https://www.researchgate.net/publication/285470001_Chitosan_membrane_as_an_oil_carrier_Spectroscopi c_and_modeling_analyses.

46. Farrage, N.; Oraby, A.; Abdelrazek, E.; Atta, D. Synthesis, characterization of Ag@ PANI core-shell nanostructures using solid state polymerization method. Biointerface Res. Appl. Chem 2019, 9, 3934-3941, https://doi.org/10.33263/briac93.934941.

47. Refaat, A.; Atta, D.; Osman, O.; Mahmoud, A.A.; El-Kohadary, S.; Malek, W.; Ferretti, M.; Elhaes, H.; Ibrahim, M. Analytical and computational study of three coptic icons in Saint Mercurius Monastery, Egypt. Biointerface Research in Applied Chemistry 2019, 9, 4685-4698, https://doi.org/10.33263/briac96.685698. 